\title{
Die topkwark*
}

\author{
R. Tegen \\ Departement Fisika, Universiteit van die Witwatersrand, Posbus 3, Wits, 2050
}

Ontrang 28 Oktober 1997: aanvaar 26 Maart 1998

\section{UITTREKSEL}

'n Oorsig van die belangrikheid van die onlangs ontdekte topkwark by Fermilab in Chicago word gegee. Daar word aangetoon dat die topkwark belangrik is in fisika van die Oerknal, oftewel "Big Bang", en in die Standaard Model van Elementêredeeltjie-fisika. Toepaslike literatuur vir verdere studie kan van die lys van verwysings in hierdie kort, nietegniese artikel, nagegaan word.

\section{Anstract}

\section{The top-quark}

The importance of the recent discovery of the top-quark at Fermilab in Chicago is reviewed. It is shown that the top-quark is important for Big-Bang physics as well as for the Standard Model of Elementary Particle Physics. Relevant literature for further reading can be traced from the list of references given in this short, non-technical article.

Op 2 Maart 1995 het die lang soektog na die "finale letter in die alfabet van die Standaard Model van deeltjies" geëindig. ${ }^{\text {. Twee }}$ eksperimentele navorsingsgroepe, die sogenaamde CDF
(Collider Detector by Fermilab)-grocp en dic Do (Dee-zero)groep, wat albei by die Fermilab Tevatron-proton-antiprotonversneller navorsing gedoen het, het op daardie dag aangekondig

"Opgedra aan professor Richard Lemmer by geleentheid van sy vyf-en-sestigste verjaardag. 
dat hulle die topkwark linaal gevind het. ${ }^{2}$ Sedert die cerste indirekte bepaling $(\sim 1989)$ van die topkwark ( 1 ) se massa, het die metings van hierdic massa stelselmatig verbeter na dic huidige waarde van $m_{t}=(180 \pm 12) \mathrm{GeV}^{3,}$ (sien figuur 1). Dic massa van die topkwark is dus ongeveer dié van 'n goudatoom!

Voordat die eksperimentele metodes van die "jag op die topkwark" bespreck word, word die rol van die $t$-kwark binne dic raamwerk van die Standaard Model (SM) vir clementêre decltjies beskou. Dic SM beskryl hoe die fundamentele wisselwerkings tussen elementêre declijies (kwarke en leptone) voortgeplant word deur die uitruil van " "eik"-bosone. ${ }^{c}$ Beide kwarke en leptone verskyn as drie docblette van declijies soos uilecngesit in figuur 2. So 'n doeblet stel 'n kwark- of Ieplongenerasie daar. Dic lede binne elke docblet vertoon soortgelyke eienskappc, maar verskil nocmenswaardig in massa (sien dic massapatroon in figuur $3 \mathrm{cn}$ dic bespreking in verwysings 4-6). Elke lepton-docblet bestaan uit 'n clcktries-gelaaide decltjic [clekıron $(e)$, muon $(\mu)$ of dic tau lepton $(\tau)$ ] plus 'n neutralc metgesel, dic sogenaamde neutrino $(v)$. . Die neutrino's sell skyn

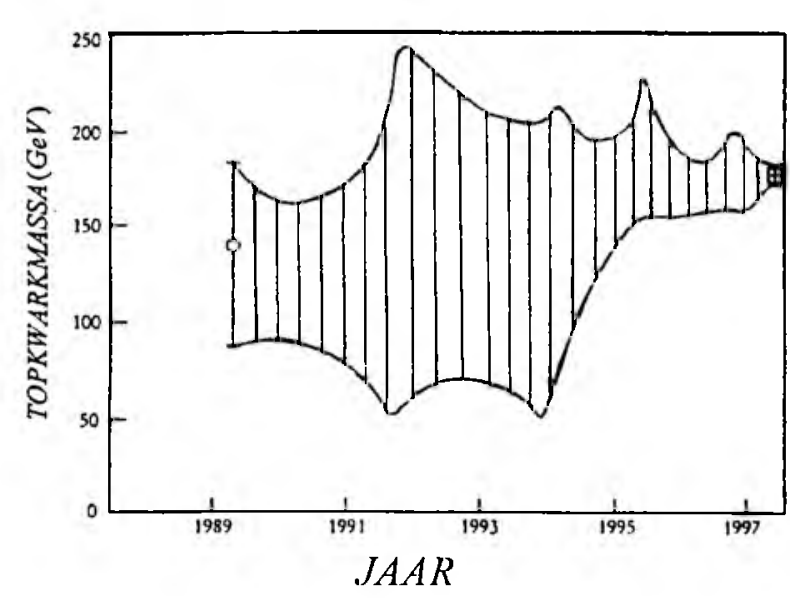

FIGUUR 1: Topkwarkmassa teenoor jaar waarin dit gemeet is. Die ingekleurde oppervlak stel die onsekerheid in die massabepaling voor; wat hier langs die tyd-as as kontinu daargestel word. amper massaloos te wees: limiete op die neutrinomassas verskyn in figuur 3.

Wisselwerkings tussen elementêre decltjies kan ingedeel word in (i) sterk kragte (ol kernkragte) wat oorgedra word deur massalose "gluone", (ii) elektromagnetiese kragte wat deur massalose folone oorgedra word, en (iii) "swak" kragte wat oorgedra word deur die swalar $W$ en $Z$ eikbosone. 'n Verdere belangrike bestanddecl van die SM is dic (tans nog hipotetiese) Higgs-boson. Dic Higgs-boson veroorsalak dat dic $W$ en $Z$ massief word ( -100 protonmassas), anders sou hulle, net soos dic foton, massaloos gebly het. Dic leit dat hierdie twee cikbosone massief word, veroorsaak dat daar 'n simmetrieverbreking tussen swak en elcktromagneticse kragte ontstaan. Nog verder, dic leit dat dic topkwark se massa numeries soortgelyk is aan die energieskaal (van ongeveer $100 \mathrm{GcV}$ ) van die clcktro-swak simmetricverbrekingsmeganisme suggerecr dat dic massa van dic topkwark saamhang mel dic oorsprong van dic clektro-swak simmetricverbreking. Dic Higgs-boson, wat sover nog nie waargeneem is nic, koppel hoofsaak lik met dic topkwark en sy antideclijic dic antitopkwark (i) , d.w.s. met $t \bar{l}$ parc. Dic Higgs-meganisme verbind dic massa van die lopkwark $m$, dus met 'n hele spektrum van moontlike Higgs-massas wat iewers tussen 100 en $500 \mathrm{GeV}$ kan wees.

Die fermione (d.w.s. kwarke en leptone) in afsonderlike generasies dra kwantumgetalle wat verhinder dat hulle maklik omskep kan word in fermione van 'n ander generasic. Byvoorbecld, die leptone $e, \mu$, $\tau$ en hul neutrinometgeselle dra kwantumgetalle $L_{e, \mu t . t}$ wat eksak behoue bly. Dic kwarke dra soorgelyke kwantumgetalle. Dit het die gebruik geword om hicrdic kwantumgetalle die "kwark-geure" te noem. Hulle behels die twee moontlike ladingstoestande (2/3 of $-1 / 3)$, die vreemdheid ("strangeness") S, sjarme ("charm") C, skoonheid ("bcauty", of "bottom") B, cn top ("topness", of "truth") T. Die kwantumgetalle S,C,B,T neem die waardes \pm 1 aan, waar die teken só gekies word dat dit saamval met die teken van die kwark se lading. Volgens figuur 2 is die ladingstocstand van die $t-k$ wark $+2 / 3$, die van die $b-k$ wark $-1 / 3$. Dus is $T=+1$ vir die $t-k$ wark, $e n$ $B=-1$ vir die $b-k$ wark.

In die cenvoudigste kwarkmodelle van hadrones ${ }^{\text {w }}$ word mesone (pion $\pi$, omega $\omega$, sigma $\sigma$ ens.) opgebou uit gebonde kwarkantikwark-pare $q_{1} \dot{q}_{2}$, terwyl die barione (proton, neutron, hiperone, cns.) 'n gebonde sisteem van drie kwarke $q_{1}, q_{2}, q_{3}$ is. Volgens hierdie skema sal die top-meson $T^{\prime}(\sim 175 \mathrm{GeV})=t \overline{\text { (wat terloops }}$ nog nie waargeneem is nie) byvoorbecld, verhinder word om in

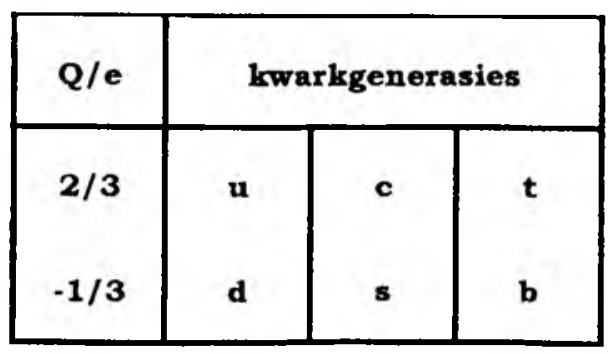

leptongenerasies

\begin{tabular}{|c|c|c|c|}
\hline 0 & $v_{e}$ & $v_{\mu}$ & $v_{\tau}$ \\
-1 & e & $\mu$ & $\tau$ \\
\hline
\end{tabular}

FIGUUR 2: Fermionladings (in eenhede van die basiese lading e) vir die drie generasies.

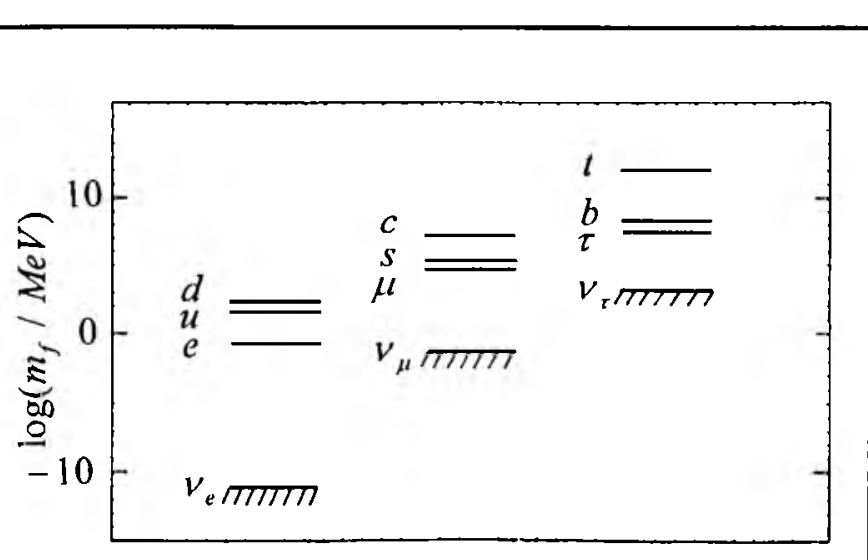

\section{fermiongenerasies}

FIGUUR 3: Fermionmassas vir leprone en kwarke binne die drie generasies. Die ingekleurde dele dui die boonste grense aan. 'n Logaritmiese skaal is langs die vertikale as aangebring. 
'n veel ligter $B$-meson, $B^{-}(\sim 4.5 \mathrm{GeV})=b i$, te kan verval. Dit sou vereis dat $t \bar{i} \rightarrow b \bar{i}$ wat 'n geurverandering $t \rightarrow b$ sou meebring. Dit kan alleen deur bemiddeling van die swak wisselwerking plaasvind. Dan word die veranderinge $\Delta T \neq 0$ en $\Delta B \neq 0$ toelaatbaar vir die T-meson se verval.

Daar word nou teruggekeer na die deurslaggewende eksperimente wat die ontdekking van die topkwark tot gevolg gehad het. Soos gemeld is hierdie eksperimente op Fermilab se Tevatron uitgevocr. Dic beginsel van hierdic eksperimente is om ' $n$ bundel van hoë-energie protone $(900 \mathrm{GcV})$ 'n kop aan kop botsing te laat ondergaan met 'n bundel antiprotone van dieselfde energie, wat in die teenoorgestelde rigting beweeg, om sodoende $\bar{t}$ pare (onder andere) op te wek. Hierdic pare verval byna onmiddellik, maar laat "vingerafdrukke" na in die vorm van vervalprodukte,

$$
p \bar{p} \rightarrow t \bar{t}+\text { enigiets, } t \rightarrow b W^{+}, \bar{t} \rightarrow W^{-} \bar{b}, W^{-} \rightarrow \mu^{-} v_{\mu}, W^{+} \rightarrow u d
$$

soos uiteengesit in figuur 4. Die kwarke in die vervalprodukte $(\vec{b}, b, u, \vec{d})$ veroorsaak kenmerkende, dun bundels ("jets") deeltjies. Hierdie deeltjiebundels vorm omdat elke kwark wat geskep word, aansluit' by 'n metgesel-antikwark van die opgewekte vakuum, om sodoende hoofsaaklik pione te vorm (sien figuur 5). In hierdie soort opname kan die $b$-kwark byvoorbeeld uitgeken word aan of die kort leeftyd daarvan (wat gekenmerk word deur 'n kort deeltjiebundelspoor wat by dic $p \bar{p}$ botsingspunt ontstaan en by die vervalspunt eindig) óf deur middel van die (semileptoniese) vervalprodukte. Die $b$-kwark se leeftyd is veel langer as dié van die topkwark. Hierdie feit gee die $b$ genoeg tyd om homself met 'n ligte antik wark te "klee" (soos in figuur 5) om sodoende 'n B-meson tc bou, wat dan 'n kort, maar waarneembare deeltjiespoor in die telapparaat nalaat. Dus kan die B-meson "ge-eien" word deur die ontstaan van 'n kenmerkende vervalspatroon, omtrent een millimeter van die skeppingspunt af. Die $W$-boson, daarenteen, besit 'n leeftyd soortgelyk aan dié van die topkwark: dit het 'n kans van $2: 3$ om in 'n $q_{1} \tilde{q}_{2}$ paar te verval, wat dan hulle teenwoordigheid

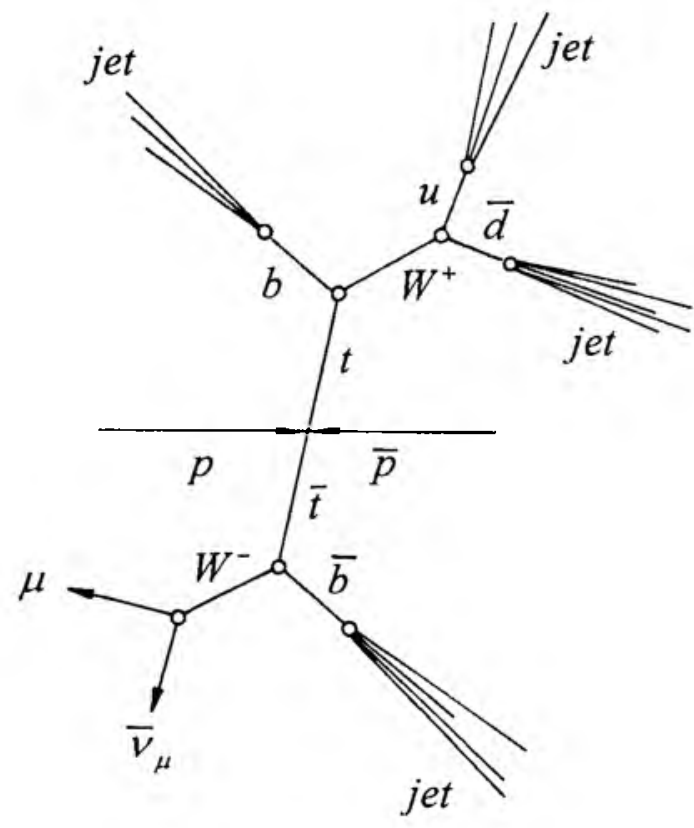

FIGUUR 4: Een van die proton-antiproton-botsings wat teruggevoer kon word na 'n top-antitop-paar wat by die wisselwerkingspunt verskyn het. Verwys na die hoofartikel. aankondig as twee dun decltjiespore. Vir die oorblywende $1: 3$ kans verval die $W$ in leptonpare - 'n hoë-energie-gelaaide lepton wat deur 'n onsigbare neutrino vergesel word, soos aangedui word in figuur 4 . Die oorblywende vervalsmoontlikhede is

$$
\bar{t} \rightarrow I_{1}^{+} \Gamma_{2} b \bar{b} \varepsilon_{r}, l_{i}^{+} b \bar{b} \varepsilon_{T}, b \bar{b} 4 \text { deeltjiespore }
$$

waar $I_{1.2}=e, \mu, \tau$. Dic simbool $\varepsilon_{T}$ is kortskrif om aan te toon dat 'n aansienlike hoeveelheid energic ontbreek in dic rigting loodreg op die bundelrigting. Daar word aanvaar dat hierdic energie weggedra word deur die neutrino's.

Dic jaar (1995) van dic kunsmatige opwekking van die topkwark by Fermilab was nie die eerste keer dat hierdie deeltjie sy verskyning in die heclal gemaak het nie. Tydens die eerste fase van die Oerknal, oftewel "Big Bang", ruim $10^{10}$ jaar terug, is topkwarke in groot getalle geskep. Tussen $10^{-35}$ sekonde (toe die materic-antimaterie-asimmetric te voorskyn gekom het) en $10^{3}$ sekonde (toc helium en deuterium gevorm is) ná die ontplofling het die heelal 'n fase bereik waar materic bestaan het uit kwarke en leptone in termiese ewewig met die eikbosone van SM. Die termiese energieë het in daardie stadium tussen $10^{14} \mathrm{en} 10^{-4} \mathrm{GeV}$ geval, wat ooreenkom met temperature tussen $10^{27} \mathrm{~K}$ en $10^{4} \mathrm{~K} .^{7}$ Verder word $t$ en $i$ kwarke (onder andere) gedurig virtueel opgewek en vernietig volgens die kringloop

$$
\left(\begin{array}{c}
\gamma \\
Z^{0}
\end{array}\right) \rightarrow\left(\begin{array}{c}
i \bar{i} \\
b \bar{b} \\
\dot{u} \bar{u}
\end{array}\right) \rightarrow\left(\begin{array}{c}
\gamma \\
Z^{0}
\end{array}\right) \rightarrow\left(\begin{array}{c}
t \bar{i} \\
b \bar{b} \\
\dot{u} \bar{i}
\end{array}\right) \rightarrow\left(\begin{array}{c}
\gamma \\
Z^{\prime}
\end{array}\right) \rightarrow \ldots
$$

In woorde, die voortplanting van 'n foton of 'n ongelaaide eikboson $Z^{\prime}$ kan die vakuum opwek (polariseer) deur virtuele kwark-antikwark-pare daaruit op te wek. Hierdie pare vernietig mekaar dan weer binne 'n tydsduur wat vasgelê word deur die Heisenberg-onsekerheidsbeginsel, om net weer opgewek te word

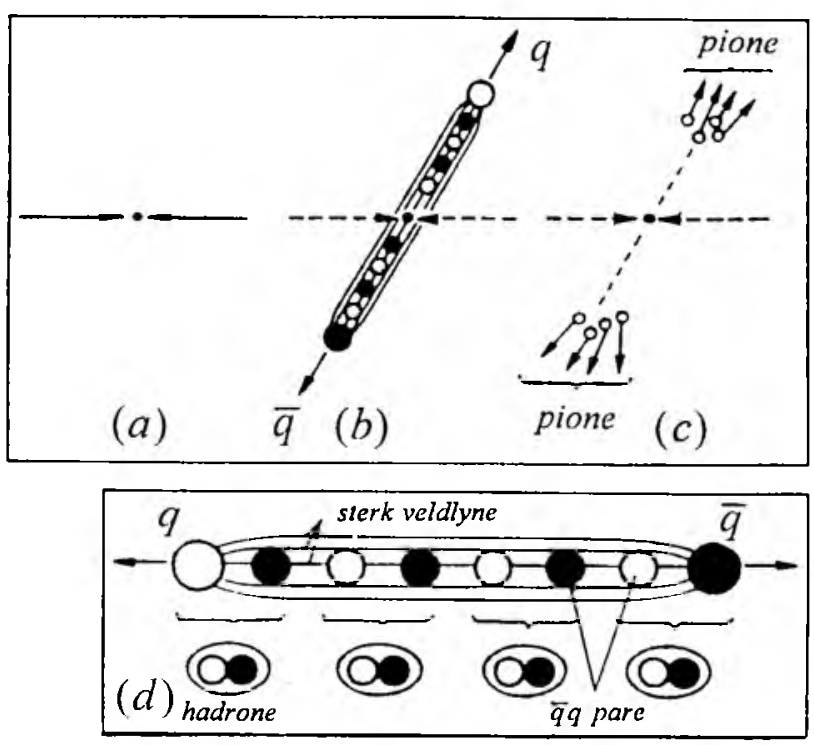

FIGUUR 5: Die ontstaan van deeltjiebundelspore ("jets"). (a) deeltjie-antideeltjie botsings in die massapuntsisteem; (b) 'n kwark-antikwark-paar verskyn en het tot gevolg 'n hele aantal gewone (ligte) kwark-antikwark-pare binne 'n silindervormige gebied waar 'n hoë digtheid van gluon-veldlyne heers; (c) gewone (d.w.s. ligte) hadrone (hoofsaaklik pione) het gevorm en word langs die kwark-antikwark-bundel-as uitgestraal; (d) vergroting van die silindervormige gluonveld gebied waar die hadrone vorm in (b). 
ad infinitum. Baie kwalitatiefkan ons ons miskien dic volgende meganiese becld van hierdie gebeure voorstel: 'n sterk wind waai oor'n spieëlgladde see en tel waterdruppels op (kwarke) om sodoende "waterholtes" (antikwarke) in die see se oppervlak te skep. Dan val hierdie druppels terug en die see word weer glad met die lugstroom wat daaroor beweeg.

Soos reeds aangedui (figuur 2), voltooi dic topkwark dic derde generasic van kwarke. Maar waarom net drie generasies"? Teoreties is dit só dat eikveldteorieè wat "hernormaliseerbaar" is (d.w.s. teoretiese ramwerke waarin die divergensies wat voorkom ten minste hantecrbaar is) 'n streng "anomalie"voorwaarde' neerlê op die fundamentele fermionvelde van daardie veldteoric, naamlik

$$
\sum_{1} Q_{1}+3 \sum_{q} Q_{q}=0
$$

Vegelyking (1) verwys gladnic na die lepton of kwarkmassas nic. Alleen die leptoniesc $(Q)$ en kwarkladings $\left(Q_{t}\right)$ is betrokke. Vanselfsprekend geld (1) vir elke generasic afsonderlik,

$$
-1+0+3 \times(2 / 3+(-1 / 3))=0
$$

sodat vgl. (I) geen beperking op die moontlike aantal generasies vereis nie. 'n Ander interessante aspek van vgl. (1) is dic faktor "3" voor die kwarkladings. Elke kwark kom in drie "kleure" (rooi, groen, blou") voor, sodat byvoorbeeld 'n " $u$ " of op-kwark se bydrac tot 'n fermionlus dric keer verskyn, aangesien die rooi, groen en blou op-kwark clk 'n lading van twee derdes bydra.

Terwyl dic "anomalic", soos daargestel word deur vgl. (1) ongevoclig is ten opsigte van dic aantal generasies, is hierdie stelling onwaar vir die verval ${ }^{k}$ van dic $Z$-boson. Die gemele leeftyd van hicrdie boson kan alleen vereenselwig word met dic bestaan van dric generasies van fermione. Daarby is dit ook bekend dat die materic-antimateric-asimmetric, wat in dic huidige heclal waargenecm word, ontstaan as gevolg van 'n baic klein $\left(10^{-4}\right)$ ladingsuitruil-pariteitverbreking. Hicrdic verbreking vereis ook tenminste dric docblette. Maar bo en behalwe hierdic eksperimentele waarnemings is daar tans geen deurslaggewende bewys vir net drie generasies binne die raamwerk van SM nie. Dus die antwoord op dic vraag "Waarom net drie docblette?" sal dalk lê in 'n veralgemening van die huidige teoricê,, waar materievelde (fermione) en eikvelde (eikbosons) verenig word binne 'n teoretiese raamwerk wat as supersimmetrie bekend staan. Hierdie teoric wag nog op eksperimentele bevestiging.

\section{Summary}

The importance of the recent discovery of the top-quark at Fermilab in Chicago is reviewed. The decay signature op the $p \bar{p}$ pairs is discussed which lead to the discovery, It is shown that the top-quark is important for Big-Bang physics as well as for the Standard Model (SM) of Elementary Particle Physics. The top quark completes the third fermion generation and as such renders the SM anomaly-free, which is an important criterion for a renormalizable ficld theory. The top-quark's mass is related to the stil undiscovered Higgs sector of the SM. The relevant literature for further reading can be traced from the list of relerences given in this short, non-technical article.

\section{DANKBETUIGING}

Richard Lemmer word bedank vir sy bydrae gelewer ten opsigte van taalkundige versorging van die artikel, sowel as gewaardeerde besprekings van die wetenskaplike inhoud van die werk.

\section{VOETNOTE}

" Ongeveer nege maande vrocër was daar reeds voorlopige aanduidlings van die bestaan van die topk wark.'

b Tydens die tweejaarlikse internasionale "Rochester"-konferensie (wat hierdie jaar in Warskou, Poland plaasgevind het) is 'n nuwe bepaling van $m_{1}=(175 \pm 6) \mathrm{GeV}$ deur $\mathrm{CDF}$ en $\mathrm{DO}$ aangekondig. Die energie-eenheid "I GeV" is net groter as die rusmassa van die waterstofatoom, wat op sy beurt hoofsaaklik die rusmassa van die proton daarstel.

c Die term "eik(ing)" verwys na 'n simmetrie-eienskap van sulke bosone, naanlik 'n invariansic onder lokale veranderings in die fase van hulle tocstandsvektor

d Tot op hede is dit nog nie bewys dat die leptoniese metgesel $v_{t}$ van dic topkwark verskillend is van of dic $v_{e}$ (elektron-neutrino) of dic $v_{\mu}$ (muon-neutrino) nic. Een eksperimetele bewys hiervoor sou 'n omgekeerde beta-verval-eksperiment vereis, waar geen elektron of muon in dic finale toestand verskyn nic

$e$ Byvoorbeeld, ' $n \mu$ van massa $106 \mathrm{MeV}$ kan nie in 'n elektron van massa $0.5 \mathrm{McV}$ omskep word tensy dit vergesel word deur 'n lepton van elk van dic ander generasies nie.

$f$ Quark flavours.

g "Hadron" verwys gemeenskaplik na mesone ( $\pi,(1) \ldots$ ens.) en barione (proton, neutron, hiperone, ens.).

" Hierdie proses staan bekend as "hadronisasie", d.w.s. die skepping van hadrone.

$i$ Sulke deeltijes kan dus nie direk waargeneem word nie.

$j$ Tegnies sorg hierdic voorwaarde daarvoor dat die divergensies wat ontstaan in hoër orde diagramme (wat fermionlusse bevat wat op hulle beurt die sogenaande $\gamma_{5}$ of "Adler-Bell-Jackiw" anomalie tot gevolg het) eksak uitgekansellecr word

$k$ Hierdie verval is 'n twee-stap proses: $\mathrm{Z} \rightarrow \sum_{i=1}^{\mathrm{i}} 4, \bar{q}_{i} \rightarrow$ hadrone.

\section{IITERATUURVERWYSINGS}

1. CERN Courier (1995). Top quark discovered, 35(3), I.

2. Abachi, S. et al. (D0 collaboration) (1995). Search for high mass top) quark production in pp collisions at $\sqrt{s}=1.8 \mathrm{TeV}$. Phys. Rev. Lett., 74, 2422-2426; Abe, F. et al. (CDF collaboration) (1995). Observation of top quark production in pp collisions with the collider detector at Fermilab, Phys. Rev. Letl. 74, 2626-2631.

3. Barnet1, R.M. et al. (Particle Data Group) (1996). Review of Particle Properties, Phys. Rev., D54, 1-720.

4. Schwartz, D., Tegen, R. (1992). Evidence for quarks, Spectrum, 30, 23-29, and references therein.

5. Schwartz, D., Tegen, R. (1993). A periodic table of hadrons under the quark model, Spectrum. 31, 34-45, and references therein.

6. Tegen, R. (1995). On the mass hierarchy of fundamental particles, S. Afr.J.SC., 91, 265-270.

7. Ellis, J. (1982). Grand Unified Theories in Cosmology: Phil. Trans. Roy. Soc. London A 307, 21 -32. 